\title{
Social Network, Facebook Use and Loneliness: A Comparative Analysis Between Public and Private University Students in Bangladesh
}

\author{
Bezon Kumar, ", Purnima Banik², Md. Aminul Islam³ \\ ${ }^{1}$ Department of Economics, Rabindra University, Bangladesh, Sirajganj, Bangladesh \\ ${ }^{2}$ Department of Information Science and Library Management, Rajshahi University, Rajshahi, Bangladesh \\ ${ }^{3}$ Department of Media Studies and Journalism, University of Liberal Arts Bangladesh, Dhaka, Bangladesh \\ Email address: \\ bezon.kumar3@gmail.com (B. Kumar), banik.ru10@gmail.com (P. Banik) \\ ${ }^{*}$ Corresponding author
}

\section{To cite this article:}

Bezon Kumar, Purnima Banik, Md. Aminul Islam. Social Network, Facebook Use and Loneliness: A Comparative Analysis Between Public and Private University Students in Bangladesh. International Journal of Psychological and Brain Sciences. Vol. 4, No. 2, 2019 , pp. $20-28$. doi: 10.11648/j.ijpbs.20190402.13

Received: April 25, 2019; Accepted: June 3, 2019; Published: June 12, 2019

\begin{abstract}
The study mainly explores the level of real life social network, Facebook use and loneliness of the university students in Bangladesh. In addition, the study examines the factors affecting loneliness of the students. To achieve these objectives, the study uses primary data collected from 380 students and employs several methods. Firstly, the study employs Lubben Social Network Scale and UCLA loneliness scale to measure the level of real life social network and loneliness, respectively. Secondly, the study uses a linear regression model estimated through OLS method to find out the factors affecting loneliness of the students. The study finds that although aggregately students are averagely engaged in real life social network in the study area, public university students are relatively more engaged in real life social network than that of private university students. The study also finds that aggregately students in the study area suffer from loneliness moderately where private university students suffer more than that of public university students. Moreover, the study finds that the level of loneliness is increased by 3.27 and 3.47 if students use Facebook one hour more per day and students read in private university, respectively while the level of loneliness is decreased by 4.61 if the level of real life social network is increased by one. Therefore, the study suggests the students to be careful in using Facebook and to be engaged more in real life social network in order to get rid of the adverse effects of loneliness.
\end{abstract}

Keywords: Facebook Use, Social Network, Loneliness, UCLA Loneliness Scale, LSNS, Bangladesh

\section{Introduction}

Human being is different from other animals as its aspiration to have meaningful social connections. With the blessings of new communication technologies, today people are more allied to one another than before. Absence of connection causes severe pain in the mind and leads to a sense of loneliness which is not less than the pain in the body [1]. Feeling lonely is more than just unpleasant for those who desire to be surrounded by warm relationships [2]. Feeling lonely or loneliness deteriorates the productivity of human being which ultimately decelerates the economic growth of a country [3]. Although scholars have notified that loneliness or lonely people are mostly found in developed countries, it is also found in developing countries like Bangladesh recently. Loneliness is not only found among elderly aged people but also among young generation like school, college and university students [4]. In the case of university students, loneliness is notably affecting their academic performance [5-6]. If a student fails to concentrate in education and to build up a good platform of knowledge due to loneliness, he or she will not be able to contribute to the national development. Therefore, measurement of loneliness has received considerable attention to the researchers.

Students' loneliness is affected by many factors like social, 
economic, psychological, environmental and personal factors. Although these factors strongly influence students' loneliness, these factors vary from person to person and place to place. Previous studies highlights on different factors like age, sex, years of study, uses of social media, participation in co-curricular activities, romantic relationship, living with family, psychological, economic and social supports and so on. Although very few studies on uses of social media and loneliness have been carried out in the context of Bangladesh $[3,7]$, till now some areas are unexplored and many gaps are found in those literature. Thus, the present study is an effort to fill up the previous gaps in a way that it is the first research in which two variables "types of university" and "real life social network" are studied. To the best of knowledge, the core contribution of this paper is that for the first time this study is going to comparative analyze on real life social network, Facebook use and loneliness between public and private university students. This paper may be helpful for the students, parents, teachers and policymakers to design and implement the policies to improve students' mental health or to remove loneliness by growing real life social network and optimal using of social media.

\section{Literature Review}

This section presents a deep review of earlier literature on social network, social media and loneliness. After a deliberate review of literature, it is found that different researchers have applied different methods and found different findings which are stated in this section by turns. For a comprehensive understanding the role of social media in mental health, a theoretical approach can be outlined as the interpersonal-connection-behaviors framework. Social media sites can benefit people when they use it for meaningful social connections. On the contrary, the use of the sites can cause harm through multiple ways such as isolation and social comparison. In the context of Bangladesh, there are few studies on this ongoing issue [3, 7]. Ahmed [3] found that mediating role of timeline browsing in the relationship between loneliness and mental health, and this relationship is moderated by gender. Saha and Khanam [7] revealed that students used Facebook as a response to loneliness and at the same time, they have become lonely by using Facebook as they use Facebook in spite of being accompanied by their friends and family members and they contact with friends more via Facebook than face-to-face.

Besides the context of Bangladesh, a number of studies are found in the global context. Like, Nowland et al. [8] noted that the relationship between loneliness and social internet use is bidirectional and dynamic. In an online social networking experiment, Deters and Mehl [9] found that status updating activities on Facebook decrease loneliness. Scott, et al. [10] found that there is positive relationship between posting photo and narcissism. However, their results reveal that in the case of loneliness and shyness the relationship is negative. Meanwhile, in another study, Masthi et al. [11] found that narcissists are more frequently update about their achievements, diet, exercise and individuals with outgoing characteristics post more frequently update about their social activities. There is also some contrasting views about impact of social media on face-to-face connections. Some researchers note that more interactions on social media are replacing face-to-face connections. Meanwhile, other researchers argue that social media does not decrease face-toface interactions [12].

In another theoretical model, Lim and Kim [13] found that one's grandiosity as reflected on Facebook significantly affects other users' loneliness through malicious envy. A study by Satici [14] provides evidence of indirect effects of Facebook addiction on subjective well-being fully mediated by shyness and loneliness. The study also found that bootstrapping showed that Facebook addiction exerted a significant indirect effect on subjective well-being via shyness and loneliness. Wang et al. [15] found that active Facebook use predicted decreased social/emotional loneliness among low to moderate users and increased social/emotional loneliness among heavy users. In addition, the study found that emotional loneliness predicted higher active Facebook use among lonely adolescents. Wohn and Larose [6] found that compulsive use of Facebook had a stronger association with academic motivation than habitual use of Facebook, but neither was directly correlated with academic performance. Contrarily, the study also found that too much time spent on Facebook was weakly but directly associated with poorer perceived academic performance. Loneliness was a stronger indicator of college adjustment than any dimension of Facebook usage [6]. Necka and Cacioppo [16] found that lonely people express a preference for using the internet for social interaction and are more likely to use the internet in a way that displaces time spent in offline social activities.

While Ozdemir and Tuncay [17] showed that there were significant relationships among romantic relationship, parents' status and loneliness, Daniel [18] found a significant relationship was also found between loneliness and depression. Hon and Chua [19] showed that: 1) lonely students were more likely to fear and perceived less reward in communicating face-to-face and 2) loneliness was more dominant to predict face-to-face communication instead of Facebook use. Penning et al. [20] found that the relative utility of the DJG scale for research involving middle-aged and older adults but suggested a need for attention to the implications of method effects associated with item wording and lack of measurement invariance with respect to item residuals. Kiralp and Serin [21] found that students who get socio-economic supports have lower loneliness while the level of loneliness is higher when they do not get psychological support. Basaran [22] revealed that recreational activities were specified to have positive effect on increasing the self-esteem level and decreasing loneliness level of the prisoners. Ozgur et al. [23] found a significant relationship was found between the level of problematic Internet use and loneliness. Ilhan [24] indicated that predictive power of masculinity was significant on loneliness 
only for men.

Similarly, Clayton et al. [25] showed that anxiousness, alcohol use, and marijuana use predicted emotional attachment to Facebook. They also found that loneliness and anxiousness, but not alcohol or marijuana use, predicted individuals' connections with others using Facebook. Zaffar, et al. [26] revealed that there is linear interaction between Facebook addiction and anxiety as well as depression, however there was no correlation found between Facebook addiction, loneliness and academic performance. Kuiper, et al. [27] found that social network size and loneliness do not predict cognitive decline in depressed older adults. Blanchnio, et al. [28] indicated differences in the role of loneliness and friendship in Facebook intrusion, depending on the country. Among young Polish people, friendship decreases loneliness and loneliness decreases Facebook intrusion. Bruke and Kraut [29] suggested that people derive benefits from online communication, as long it comes from people they care about and has been tailored for them. Valtorta, et al. [30] revealed that the classification of social relationship measures transcends disciplinary and conceptual boundaries, allowing researchers to compare tools that developed from different theoretical perspectives. Okray et al. [31] revealed that suggest that SNS use among older adults are due to virtual socialization. Age and gender are strong predictors of virtual loneliness. No reciprocal relationship was found in the study: Facebook intensity had a positive impact on loneliness and, motive for using Facebook did not have any impact on loneliness, whereas loneliness influenced neither Facebook intensity nor motive for using Facebook [32]. Balchi and Olkun [33] revealed a positive relationship between loneliness of foreigners and Facebook usage that implies social network usage is increasing with rising loneliness level.

Karakose et al. [34] revealed that students most commonly share photographs and videos on Facebook to spend leisure time. They also indicated that there is a statistical significant relationship between the time participants spend on Facebook and their Facebook addiction scores. Findings of the study suggest that both male and female students' loneliness scores are low [34]. Masthi et al. [11] revealed that private school students were more prone for social media addiction. Majority had mild addiction. Addiction was associated with behavioral changes. A multitude of physical, psychological and behavioral problems were observed among social media users. Shettar et al. [35] found that more than one-fourth (26\%) of the study participants had Facebook addiction and 33\% had a possibility of Facebook addiction. They have also found that there was a significant positive correlation between severity of Facebook addiction and extent of experience of loneliness. Pittman [36] found that frequency of social media use initially predicted decreased loneliness and increased happiness, but once perceived intimacy was factored in, it was a more significant predictor than frequency of use.

Keeping in view the literature, this study is organized to assess the level of real life social network and loneliness, and the factors affecting the loneliness of the university students in Bangladesh.

\section{Methodology}

\subsection{Data and Sample Selection}

The study is mainly based on primary data. To carry out the study, Rajshahi district of Bangladesh is selected randomly as the study area. There are four universities in Rajshahi. In this stage, universities are divided into two strata such as public university and private university. In the stratum of public university, there are two universities while there are also two universities in private university stratum. Applying stratified random sampling method, one university from both stratum is chosen randomly. The selected universities are Rajshahi University from first stratum and Varendra University from second stratum. Rajshahi University has about 30000 students while Varendra University has about 5000 students. In this stage, 450 copies of a well-structured questionnaire is proportionally and randomly distributed among students in each university in January, 2019. Finally, only 405 questionnaires were got back. After sorting, coding and editing, 380 questionnaires are used for the final data analysis. The rest questionnaires were omitted due to errors.

\subsection{Empirical Methods}

\subsubsection{Lubben Social Network Scale}

The study firstly uses the Lubben Social Network Scale to measure the level of real life social network of students following Hon and Chua [19], Jobe and White [37] and Cecen [38]. In this study, six items Lubben Social Network Scale (LSNS-6) is used whose score ranges from 0 to 30 . The score zero means student is not engaged in real life social network while the score 30 means student is highly engaged in real life social network. In this study, the estimated score of this scale is divided into three categories. Such as 0 to 10.00 (lower level of social network), 10.01 to 20.00 (average level of social network) and 20.01 to 30.00 (higher level of social network).

\subsubsection{UCLA Loneliness Scale}

Besides measuring the level of real life social network, the study also measures the level of loneliness of students using twenty items UCLA loneliness scale following Rusell, et al. [39], Basarn [22], Ozgur et al. [23], Penning et al. [20] and Ilhan [24]. Among twenty items, there are 10 negatively stated (lonely) and 10 positively stated (non-lonely) items. The score of twenty items UCLA loneliness scale ranges from 0 to 60 . The score zero means student is not lonely while the score 60 means student is highly lonely. In this study, the estimated score of this scale is divided into three categories. Such as 0 to 20.00 (lower level of loneliness), 20.01 to 40.00 (moderate level of loneliness) and 40.01 to 60.00 (severe level of loneliness).

\subsubsection{Linear Regression Analysis}

Loneliness affects human being negatively in many ways which ultimately hampers to the socio-economic 
development of a country. Thus, it requires seeking out the factors affecting loneliness of students. Loneliness is determined by many factors. By following earlier studies, the present study considers a cause and effect relationship between loneliness and a set of explanatory variables. Since the dependent variable, loneliness, is continuous, the study applies a linear regression model estimated through OLS method following Kumar et al. [40] and Kumar [41]. Equation 1 states the relationship as follows:

$$
L_{i}=f\left(X_{i}\right)
$$

Econometrically the equation 1 can be formed as:

$$
L_{i}=X_{i}+\boldsymbol{\varepsilon}_{i}
$$

where, $\mathrm{L}_{\mathrm{i}}$, dependent variable, is loneliness and $\mathrm{X}_{\mathrm{i}}$ is a set of explanatory variables that affect the loneliness.

Therefore, the specified multiple regression model is:

$$
L_{i}=\boldsymbol{\delta}_{0}+\boldsymbol{\delta}_{1} A G+\boldsymbol{\delta}_{2} S E+\boldsymbol{\delta}_{3} S Y+\boldsymbol{\delta}_{4} T U+\boldsymbol{\delta}_{5} H F+\boldsymbol{\delta}_{6} P S+\boldsymbol{\delta}_{7} P C A+\boldsymbol{\delta}_{8} S N+\boldsymbol{\delta}_{9} P E S+\boldsymbol{\delta}_{10} R R+\boldsymbol{\varepsilon}_{i}
$$

where, $\mathrm{L}_{\mathrm{i}}$ is loneliness measured through UCLA loneliness scale, $\delta_{0} \ldots . \delta_{10}$ are parameters to be estimated and $\epsilon_{\mathrm{i}}$ is the stochastic disturbance term. The explanatory variables used in above model are explained in Table 1.

Table 1. Description of explanatory variables used in multiple regression model.

\begin{tabular}{llll}
\hline Name of Variables & Type & Measurement & Expected Sign \\
\hline Age (AG) & Continuous & Age of the student (years) & - \\
Sex (SE) & Dummy & Sex of the student (1 for female and 0, otherwise) & + \\
Study year (SY) & Continuous & Students' studying year (years) & - \\
Types of university (TU) & Dummy & $\begin{array}{l}1 \text { if student reads in private university, 0 if student reads in public } \\
\text { university }\end{array}$ & + \\
Hours on Facebook (HF) & Continuous & Total time spent on Facebook per day (hours) & + \\
Parents' status (PS) & Dummy & 1 if student's parents is divorced, 0 otherwise & + \\
Participation in co-curricular activities (PCA) & Dummy & 1 if participates in co-curricular activities, 0 otherwise & - \\
Social network (SN) & Continuous & Estimated values of Lubben Social Network Scale & - \\
Psychological and economic supports (PES) & Dummy & 1 if students get psychological and economic supports, 0 otherwise & - \\
Romantic relationship (RR) & Dummy & 1 if students have romantic relationship, 0 otherwise & - \\
\hline
\end{tabular}

All these variables and their expected sign have been considered in the regression model following earlier literature [17].

\section{Results and Discussion}

\subsection{Facebook Use Related Features}

This section presents the Facebook use related features of students like hours spent on Facebook per day, years of Facebook use,

\begin{tabular}{|c|c|c|c|}
\hline \multirow{2}{*}{ Variables } & \multirow{2}{*}{ Categories } & \multicolumn{2}{|l|}{ University } \\
\hline & & Public (\%) & Private $(\%)$ \\
\hline \multirow{4}{*}{ Years of Facebook Use } & 2.00 and below & 30.10 & 22.55 \\
\hline & 2.01 to 3.00 & 24.40 & 15.77 \\
\hline & $3.01-4.00$ & 35.30 & 29.45 \\
\hline & 4.01 and above & 11.20 & 32.23 \\
\hline \multirow{4}{*}{ Facebook used for } & Passing time & 9.50 & 28.45 \\
\hline & A kind of addiction & 3.40 & 36.63 \\
\hline & Keeping communication with others & 62.15 & 12.55 \\
\hline & Entertainment & 24.95 & 22.37 \\
\hline \multirow{3}{*}{$\begin{array}{l}\text { Activities mostly done on } \\
\text { Facebook }\end{array}$} & Making new friends & 25.30 & 29.00 \\
\hline & Viewing news feed & 69.50 & 43.44 \\
\hline & Updating photo/status & 4.20 & 27.56 \\
\hline \multirow{3}{*}{ Hours spent on Facebook per day } & 2.00 and below & 35.40 & 22.23 \\
\hline & $2.01-3.00$ & 40.20 & 37.81 \\
\hline & 3.01 and above & 24.40 & 39.96 \\
\hline \multirow{2}{*}{ Sharing of link } & Yes & 68.00 & 33.37 \\
\hline & No & 32.00 & 76.63 \\
\hline \multirow{4}{*}{$\begin{array}{l}\text { Changes of profile picture in the } \\
\text { last month }\end{array}$} & Never & 35.15 & 5.95 \\
\hline & Once & 25.15 & 13.37 \\
\hline & Twice & 30.20 & 47.05 \\
\hline & Thrice and above & 9.50 & 13.63 \\
\hline
\end{tabular}
changes of profile picture, sharing of link and so on. The results are analyzed with SPSS 23.00 and presented in the following table.

Table 2. Facebook Use Related Features of Students.

Source: Field survey, 2019 
The Table 2 shows that majority of the public university students use Facebook for 3.01 to 4.00 years while the duration of using Facebook of private university students is 4.01 and above years. Majority students of public university $(62.15 \%)$ use Facebook for keeping communication with others while private university students (36.63\%) use Facebook mostly as a kind of addiction. In addition, it is found that most of the students of both public and private university spent time on Facebook for viewing friends' update and the rate are $69.50 \%$ and $43.44 \%$, respectively. From the analysis, it is found that students of private university spent time more on Facebook than that of public university students. The study also finds that most of the students of public university (68 percent) share various links on their Facebook timeline while the figure is 33.37 percent for private university students. Interestingly, the study finds that majority students of public university $(35.15 \%)$ never change their Facebook profile picture in a month while majority of the private university students (47.05\%) change their Facebook profile picture twice a month. From the analysis, it is found that private university students are more engaged in using virtual social network or media, Facebook than public university students.

\subsection{Causes of Updating Facebook Status}

This section comparatively presents the causes of updating Facebook status between public and private university students in Bangladesh. The results are analyzed through SPSS 23.00 and presented in Table 3 which shows nine causes of updating Facebook status by the students and the percentage of total for each cause.

Table 3. Causes of Updating Facebook Status.

\begin{tabular}{lll}
\hline \multirow{2}{*}{ Reasons } & \multicolumn{2}{l}{ Percentage of Total } \\
\cline { 2 - 3 } & $\begin{array}{l}\text { Public } \\
\text { University }\end{array}$ & $\begin{array}{l}\text { Private } \\
\text { University }\end{array}$ \\
\hline To share memorable moments & 53.00 & 57.10 \\
To share useful links & 48.20 & 21.30 \\
To express joys & 37.00 & 41.00 \\
To express anger and egotism & 10.70 & 29.40 \\
To express depression & 11.80 & 26.80 \\
To remove loneliness & 13.60 & 33.60 \\
To share self-progress & 9.30 & 19.40 \\
To get like and comments & 5.80 & 15.60 \\
To earn name and fame & 3.20 & 30.20 \\
\hline
\end{tabular}

Source: Field survey, 2019

From the above table, it is found that to share memorable moments is the top most cause behind updating Facebook status for both of public $((53.00 \%)$ and private university (57\%) students. Second cause for updating Facebook status by the public university students is to share useful links while it is to express joy for private university students. On the other hand, to express joys is third cause for public university students while it is to remove loneliness for private university students. Similarly, to earn name and fame is the lowest cause of updating Facebook status by the students of public university $(3.20 \%)$ and to get like and comment $(15.60 \%)$ is for private university students. From this analysis, it is found that students update Facebook status mainly not only to express depression and remove loneliness but also for many causes. However, there is significant difference between public and private university students in causes of updating Facebook status.

\subsection{Lubben Social Network Scale}

Lubben Social network Scale (LSNS) is measured through the MS Excel 2013 and the result is presented in tabular form in the following table.

Table 4. Level of Real Life Social Network of Students.

\begin{tabular}{lll}
\hline $\begin{array}{l}\text { Levels of social } \\
\text { network }\end{array}$ & $\begin{array}{l}\text { Public University } \\
(\mathbf{\%})\end{array}$ & $\begin{array}{l}\text { Private University } \\
(\%)\end{array}$ \\
\hline Lower level & 21.50 & 24.25 \\
Average level & 49.27 & 52.67 \\
Higher level & 29.23 & 23.08 \\
Total & 100 & 100 \\
\hline
\end{tabular}

Note: The average of the level of real life social network in the study area is 16.07 for all students, 19.36 for public university students and 17.97 for private university students.

Source: Field survey, 2019

Table 4 shows that 21.50 percent public university students are engaged in lower level of real life social network while it is 24.25 percent for private university students. On the other hand, majority of the students of both public (49.27\%) and private university $(52.67 \%)$ students in the study area are averagely engaged in real life social network. Although very few students of both types of universities are highly engaged in real life social network, the percentage of public university students $(29.23 \%)$ is more than that of private university students $(23.08 \%)$.

From the analysis, it is also found that the average of the level of real life social network is 16.07 for all students, 19.36 for public university students and 17.97 for private university students. This interprets that students of public university are relatively more engaged in real life social network than that of private university students in the study area.

\subsection{UCLA Loneliness Scale}

UCLA Loneliness Scale is measured through the MS Excel 2013 and the result is presented in tabular form in the following table.

Table 5. Level of Loneliness of University Students in Bangladesh.

\begin{tabular}{lll}
\hline $\begin{array}{l}\text { Levels of } \\
\text { loneliness }\end{array}$ & Public University (\%) & Private University (\%) \\
\hline Lower level & 36.63 & 26.04 \\
Moderate level & 59.35 & 50.71 \\
Severe level & 4.02 & 23.25 \\
Total & 100 & 100 \\
\hline
\end{tabular}

Note: The average of the level of loneliness in the study area is 26.53 for all students, 19.36 for public university students and 38.63 for private university students. Source: Field survey, 2019 
Table 5 shows 36.63 percent public university students in the study area are suffering from lower level of loneliness while the rate is 26.04 percent in the case of private university students. On the other hand, it is found that most of the students in the study area are suffering from moderate level of loneliness where the rate is 59.35 percent for public university and 50.71 percent for private university. In addition, it is found that very few students of public university (4.02\%) are severely suffering from loneliness while it is quite higher for private university students (23.25\%).

From the analysis it is also found that the average of the level of loneliness in the study area is 26.53 for all students, 19.36 for public university students and 38.63 for private university students. This interprets that students of private university are relatively suffering more from loneliness in the study area.

\subsection{Factors Affecting Loneliness}

The linear regression model for exploring the factors affecting loneliness of university students is analyzed with STATA-13 and the result is presented in Table 6.

Table 6. Results of Linear Regression Model.

\begin{tabular}{llll}
\hline Variables & Coefficient & Std. Err. & t statistic \\
\hline Constant & 33.13 & 7.40 & 4.48 \\
Age & -2.32 & 1.76 & -1.32 \\
Sex*** & 6.30 & 1.378 & 4.57 \\
Study year & -0.0513 & 0.0355 & -0.14 \\
Types of university** & 3.47 & 1.27 & 0.31 \\
Hours on Facebook*** & 3.27 & 0.522 & 0.73 \\
Parents' status & 0.486 & 0.927 & 0.03 \\
Participation in co-curricular activities*** & -0.266 & 0.080 & 0.53 \\
Social network*** & -4.61 & 0.682 & -3.32 \\
Psychological and economic supports* & -1.368 & 0.671 & -6.75 \\
Romantic relationship*** & -2.18 & 1.08 & -2.03 \\
\hline
\end{tabular}

$\mathrm{F}(10,369)=83.03 ;$ Prob $>\mathrm{F}=0.000 ; \mathrm{R}^{2}=0.62 ;$ Root $\mathrm{MSE}=7.13 ; \mathrm{DW}=1.98$

Note: $* * * * *$ and $*$ means $1 \%, 5 \%$ and $10 \%$ level of significance.

Source: Field survey, 2019

The table 6 shows that the value of $R^{2}$ is 0.62 indicates that explanatory variables of the model explain the dependent variable by 62 percent. Elsewhere, the F-statistic value is 83.03 with prob $>\mathrm{F}=0.000$ brings out that the model is completely good at fitted. The study has no any heteroscedasticity problem in the data that is clarified using robust standard error action. The study also exercises VIF to detect multicollinearity problem and explicitly reveals a negative result. The Durbin Watson test $(\mathrm{DW}=1.98)$ expresses that no autocorrelation problem exists in the model. The study finds that sex, types of university, hours on Facebook, participation in co-curricular activities, social network, psychological and economic supports and romantic relationship are significant variables although all variables fulfill the expected sign except remittance.

The coefficient of sex reveals that the level of loneliness may be increased by 6.30 if the students are female which is significant at 1 percent level of significance. The rational explanation may be that female students get fewer opportunities to move outside their home. That is why they feel bored and get depressed and finally suffered from loneliness. Ozdemir and Tuncay [17] also found a positive relation between sex and loneliness although it was statistically insignificant.

Similarly, the level of loneliness may be increased by 3.47 if the students read in private university. This result is significant at 5 percent level of significance and can be interpreted by the fact that students of private universities do not get enough space to share their own views with other students in their university campus. In addition, it is found that relatively less meritorious students are getting admitted in private university in the study area. For this reason, they suffer from inferiority and often fail in competitions. As a result, they get depressed soon and consequently suffer from loneliness.

The study also finds that the level of loneliness will be increased by 3.27 if student's time spent on Facebook increased by one hour per day which is significant at 1 percent significance level. The interpretation may be such that students who spent time more on Facebook feel frustrated by seeing others' socio-economic and personal progress and finally suffer from loneliness. The result is in line with Deters and Mehl [9].

The coefficient of participation in co-curricular activities reveals that the level of loneliness may be decreased by 0.266 if students participate in co-curricular activities which is significant at 1 percent level of significance. The rational explanation may be that students who participate in cocurricular activities feel fresh and abstain from depression. As a result, their level of loneliness is lower.

The level of loneliness may be decreased by 4.61 if the students the level of students' engagement in real life social network is increased by one. This result is significant at 1 percent level of significance and can be interpreted by students who are more engaged in real life social network get enough space to exchange views with family, relatives, neighbor and so on. As a result, they feel relax and remove loneliness. Holt-Lunstad et al. [42] have also found the 
similar finding.

The study also finds that the level of loneliness will be decreased by 1.37 if students get psychological and economic supports which is significant at 10 percent significance level. The interpretation may be such that students who get psychological and economic supports feel encouraged and inspired and that is why they do not suffer from loneliness. The result is in line with Ozdemir and Tuncay [17] and Kiralp and Serin [21].

Finally, the coefficient of romantic relationship reveals that the level of loneliness may be decreased by 2.18 if students have romantic relationship which is significant at 1 percent level of significance. The rational explanation may be that students who have romantic relationship can share everything with his or her partner and feel mentally fresh which keeps them free from depression and loneliness. Ozdemir and Tuncay [17] also found the similar findings.

\section{Conclusion and Policy Recommendation}

This study addresses two separate questions. First, what is the level of real life social network and loneliness among university students in Bangladesh? Second, what are the significant factors affecting loneliness of the university students in Bangladesh? This paper contributes newly to the existing literature in a sense that this study uses new methods in finding out the factors affecting loneliness and brought a comparative analysis between public and private university students in Bangladesh. To find out the answer of the above questions, this paper uses primary data and several statistical and econometric methods and finally find some interesting results.

The results are interesting in a number of respects. Firstly, the study finds that although students in the study area (16.07) are averagely engaged in real life social network, public university students (19.36) are relatively more engaged in real life social network than that of private university students (17.97). The study also finds that students in the study area (26.53) suffer from loneliness moderately where private university students (38.63) suffer more than that of public university students (19.36). Secondly, the study finds that the level of loneliness is increased by 3.27 if students use Facebook one hour more per day while it is decreased by 4.61 if the level of real life social network is increased by one. In addition, they study finds that the level of loneliness is increased by 3.47 if a student reads in private university.

Therefore, the study suggests the students to be careful in using Facebook and to be engaged more in real life social network and romantic relationship in order to remove the adverse effects of loneliness. The study also suggests policy makers to take initiatives in providing psychological and economic supports and facilities of co-curricular activities for the students, especially for the private university students, to remove their loneliness.

\section{References}

[1] Cacioppo, J., and Patrick, W. (2009). Loneliness: Human Nature and the Need for Social Connection. New York: Norton.

[2] Islam, M. A. and Kumar, B. (2018). The relationship between Facebook use, social network and loneliness among university students in Bangladesh. Conference paper. Bangladesh. Available at: https://www.researchgate.net/publication/327623 028 The relationship between Facebook use social networ k_and_loneliness_among_university_students_in_Bangladesh.

[3] Ahmed, O. (2018). Relationship between loneliness and mental health among first-year undergraduate students: mediating role of timeline browsing and chatting on Facebook. International Journal of Contemporary Education, 1 (2): 86-94. Doi: 10.11114/ijce,vli.2.3625.

[4] Alberti, B. F. (2018). This "modern epidemic": loneliness as an emotion cluster and a neglected subject in the history of emotions. Emotion Review, 10, 242-254. $10.1177 / 1754073918768876$.

[5] Stankovska, G., Angelkovska, S. and Grncarovska, S. P. (2016). Social networks use, loneliness and academic performance among university students. BCES Conference Books, 14 (1): 255-261.

[6] Wohn, D. Y. and Larose, R. (2014). Effects of loneliness and differential usage of Facebook on college adjustment of firstyear students. Computers and Education, 76: 158-167. Doi: 0.1016/j.compedu.2014.03.018.

[7] Saha, A. R. and Khanam, D. (2017). Whether the use of Facebook is a cause or an effect of loneliness. International Journal of Humanities and Social Science Invention, 6 (10): 2319-7722.

[8] Nowland, R., Necka, E., and Cacioppo, J. (2017). Loneliness and social internet use: pathways to reconnection in a digital world? Perspectives on Psychological Science, 13, 70-87. Doi: 10.1177/1745691617713052.

[9] Deters, F., and Mehl, M. (2012). Does posting Facebook status update increase or decrease loneliness? An online social networking experiment. Social Psychological and Personality Science, 4, 579-586. 10.1177/1948550612469233.

[10] Scott, G., Boyle, E., Czerniawska, K., and Courtney, A. (2018). Posting photos on Facebook: the impact of narcissism, social anxiety, loneliness, and shyness. Personality and Individual Differences, 67-72. 10.1016/j.paid.2016.12.039

[11] Masthi, N. R. R. M., Pruthvi, S. and Mallekavn, P. (2017). A comparative study on social media addiction between public and private high school students of urban Bengaluru, India. ASEAN Journal of Psychiatry, 18 (2): 206-215.

[12] Hall, J., Kearney, M., and Xing, C. (2018). Two tests of social displacement through social media use. Information, Communication and Society, 1-18. Doi: 10.1080/1369118x.2018.1430162.

[13] Lim, M. S. and Kiim, J. (2018). Facebook users' loneliness based on different types of interpersonal relationships: Links to grandiosity and envy. Information Technology and People, 31 (3): 646-665. Doi: 10.1108/ITP-04-2016-0095. 
[14] Satici, S. A. (2019). Facebook addiction and subjective wellbeing: a study of the mediating role of shyness and loneliness. International Journal of Mental health and Addiction, 17 (1): 41-55. Available at: https://link.springer.com/article/10.1007/ s11469-017-9862-8.

[15] Wang, K., Frison, E., Eggermont, S. and Vandenbosch, L. (2018). Active public Facebook use and adolescents' feelings of loneliness: evidence for a curvilinear relationship. Journal of Adolescence, 67: 35-44. Doi: 10.1016/j.adolescence. 2018.05.008.

[16] Necka, E. A. and Cacioppo, J. T. (2018). Loneliness and social internet use: pathways to reconnection in a digital world? Perspectives on Psychological Science, 13 (1): 70-87. Doi: 10.1177/1745691617713052.

[17] Ozdemir, U and Tuncay, T. (2008). Correlated of loneliness among university students. Child and Adolescent Psychiatry and Mental health, 2 (29): 1-6. Doi: 10.1186/1753-2000-2-29.

[18] Daniel, K. (2013). Loneliness and depression among university students in Kenya. Global Journal of Human Social Science Arts and Humanities, 13 (4): 10-18.

[19] Hon, K. Y. and Chua, B. S. (2015). Are lonely undergraduate students avoiding communicating in real life but vigorous in Facebook? International Journal of Humanities and Social Science, 5 (1): 43-50.

[20] Penning, M. J., Liu, G. and Chou, P. H. B. (2014). Measuring loneliness among middle-aged and older adults: the UCLA and de jong gierveld loneliness scales. Social Indicator Research, 118: 1147-1166. Doi: 10.1007/s11205-013-0461-1.

[21] Kiralp, F. S. S. and Serin. N. B. (2017). A study of students' loneliness levels and their attachment styles. Journal of Education and Training Studies, 5 (7): 37-45. Doi: 10.11114/jets. v5i7.2395.

[22] Basaran, Z. (2016). The effect of recreational activities on the self-esteem and loneliness level of the prisoners as an alternative education. Universal Journal of Educational Research, 4 (5): 1080-1088. Doi: 10.13189/ujer.2016.040518.

[23] Ozgur, H., Demiralay, T. and Demiralay, I. (2014). Exploration of problematic internet use and loneliness among distance education students. Turkish Online Journal of Distance Education, 15 (2): 75-90.

[24] Ilhan, T. (2012). Loneliness among university students: predictive power of sex roles and attachment styles on loneliness. Educational Sciences: Theory and Practice, 12 (4): 2387-2396.

[25] Clayton, R. B., Osborne, R. E., Miller, B. K. and Oberle, C. D. (2013). Loneliness, anxiousness, and substance use as predictors of Facebook use. Computers in Human Behavior, 29: 687-693. Doi: 10.1016/j.chb.2012.12.002.

[26] Zaffar, M., Mahmood, S., Saleem, M. and Zakaria, E. (2015). Facebook addiction: relation with depression, anxiety, loneliness and academic performance of Pakistani students. Science International, 27 (3): 2496-2475.

[27] Kuiper, J. S., Smidt, N., Zuidema, S. U., Comijs, H. C., Voshaarr, R. C. O. and Zuidersma, M. (2019). A longitudinal study of the impact of social network size and loneliness on cognitive performance in depressed older adults. Aging and Mental Health, 1-9. Doi: 10.1080/13607863.2019.1571012.
[28] Blachnio, A., Przepiorka, A., Wolonciej, M., Mahmoud, A. B., Holdos, J. and Yafi, E. (2018). Loneliness, friendship, and Facebook intrusion. A study in Poland, Slovakia, Syria, Malaysia, and Ecuador. Studia Psychologica, 60 (3): 183-194. Doi 10.21909/sp.2018.03.761.

[29] Burke, M. and Kraut, R. E. (2016). The Relationship between Facebook use and well-being depends on communication type and tie strength. Journal of Computer-Mediated Communication, 21: 265-281. doi: 10.1111/jcc4.12162.

[30] Valtorta, N. K., Kanaan, M., Gilbody, S. and Hanratty, B. (2016). Loneliness, social isolation and social relationships: what are we measuring? A novel framework for classifying and comparing tools. BMJ Open, 6: 1-7. Doi: 10.1136/bmjopen-2015-010799.

[31] Okray, Z., Direktor, C. and Simsek, A. H. (2018). Social network site usage among adults: social networking status and virtual loneliness. European Journal of Psychology and Educational Research, 1 (1): 11-18. Doi: 10.12973/ejper.1.1.11.

[32] Lou, L. L., Yan, Z., Mickerson, A. and Mcmorris, R. (2012). An examination of the reciprocal relationship of loneliness and Facebook use among first-year college students. Journal of Educational Computing Research, 46 (1): 105-117. Doi: 10.2190/ec.46.1.e.

[33] Balchi, S. and Olkun, E. O. (2015). The relation between loneliness in social life and Facebook usage. 16th International Academic Conference, Amsterdam. Doi: 10.20472/IAC.2015.016.015.

[34] Karakose, T., Yirci, R., Uygun, H. and Ozdemir, T. Y. (2016). Relationship between high school students' Facebook addiction and loneliness status. Eurasia Journal of Mathematics, Science and Technology Education, 12 (9): 2419-2429. Doi: 10.12973/eurasia.2016.1557a.

[35] Shettar, M., Karkal, R., Kakunje, A., Mendonsa, R. D. and Chandran, V. V. M. (2017). Facebook addiction and loneliness in the post-graduate students of a university in southern India. International Journal of Social Psychiatry, 63 (4) 325-329. Doi: $10.1177 / 0020764017705895$.

[36] Pittman, M. (2018). Happiness, loneliness, and social media: perceived intimacy mediates the emotional benefits of platform use. The Journal of Social media in Society, 7 (2): 164-176.

[37] Jobe, L. E. and White, S. W. (2007). Loneliness, social relationships, and a broader autism phenotype in college students. Personality and Individual Differences, 42, 14791489. Doi: $10.1016 /$ j.paid.2006.10.021.

[38] Cecen, A. R. (2008). The effects of gender and loneliness levels on ways of coping among university students. College Student Journal, 42, 510-516. Available at: https://eric.ed. gov/?id=EJ816934.

[39] Russell, D., Peplau, L. A, and Cutrona, C. E. (1980). The revised UCLA loneliness scale- concurrent and discriminate validity evidence. Journal of Personality and Social Psychology, 39, 472-480. Available at: https://pdfs.semanticscholar.org/ 9a8f/3d85de78c2fe20eda64eddfb1edaefa46d24.pdf

[40] Kumar, B., Hossain, M. E. and Osmani, M. A. G. (2018). Utilization of international remittances in Bangladesh. Remittances Review, 3 (1): 5-18. Available at: https://doi.org/10.33182/rr.v3i1.424. 
[41] Kumar, B. (2019). The impact of international remittances on poverty alleviation in Bangladesh. Remittances Review, 4 (1): 67-86. Available at: https://journals.tplondon.com/index.php/ $\mathrm{rem} / \mathrm{article} / \mathrm{view} / 665$.
[42] Holt-Lunstad, J., Smith, T., Baker, M., Harris, T., and Stephenson, D. (2015). Loneliness and social isolation as risk factors for mortality. Perspectives on Psychological Science, 10, 227-237. Doi: 10.1177/1745691614568352. 